\title{
Study on Soil and Water Erosion of Xiang Xi Watershed Based on 3S Dynamic Monitoring
}

\author{
Ying Jiang, Da Xiang Xiang, Zhe Li, Xiong Fei Wen, and Xi Chi Chen
}

\begin{abstract}
S technology is the effective method to carry out the dynamic monitoring of soil and water erosion. The paper select XiangXi watershed as the study region. Firstly, extracting erosion factors like vegetation coverage, land-use types and slop information, then conducting spatial overlay analysis to extract distribution of soil erosion intensity. Finally, analysing the change tendency by using transfer matrix to provide basic data for soil and water conservation. Results suggested that the intensity of soil erosion was getting better from 2016 to 2017, the Micro-degree and Slight-degree were slightly increased, the Medium-degree and Dought-degree were slightly reduced, the Extrem-degree and Vigorous-degree were alleviated.
\end{abstract}

Index Terms - Soil and water erosion, dynamic monitoring, 3S technology, transfer matrix.

\section{INTRODUCTION}

Soil and water erosion is the principal factor for the decline of cropland productivity and the deterioration of ecological environment, which is closely related to the precipitation erosion, topographic and engineering excavation, land cover changes. Traditional monitoring method usually adopted artificial survey including statistical investigation and ground observation etc, which have high accuracy but time-consuming and low-automation, also cannot dynamic monitor for a wide range [1]. As the key technology in the global satellite monitoring system, 3S provide a new approach for soil erosion investigation, of which GPS have high precision and strong portability, RS have real-time performance, while GIS have powerful storage, calculate and analyze function. These unique advantages can effectively improve the accuracy of dynamic monitoring. $3 \mathrm{~S}$ technology has been widely applied in engineering practices in recent years. Haboudane et al [2] combined the RS with GIS to reveal the erosion spatial distribution by establishing the degradation and soil erosion map of Guadalentin basin. Zhao PengXiang et al [3] proposed a solution on watershed returning farmland to forest based on 3S technology, which improved the efficiency of small watershed dynamic monitoring. Xu Feng et al [4] took Hydropower station as example to introduce the key steps of development and construct project monitoring by using $3 \mathrm{~S}$ technology, results showed that the method can effectively obtain accurate erosion date and surface disturbance area.

Manuscript received February 23, 2018; revised April 13, 2018. This work was supported by the Basic Research Operating Expense for the Central level Non-profit Research Institutes of china (No.CKSF2016036/KJ, No.CKSF2015019/KJ), and National Scientific Fund of China (No. 41201452, No. 41401487).

The authors are with Changjiang River Scientific Research Institute, Wuhan, China (e-mail: 496396225@qq.com).
Although 3S technology has become an effective measure to monitor the soil and water erosion, the efficiency interpretation and accuracy of erosion monitoring still need improvement in actual application.

\section{Methodology}

\section{A. The Regional Overview}

The paper select XiangXi watershed flowing through ZiGui country as study region,which occupied area above $99.92 \mathrm{~km}^{2}$. It's the first tributary of the Three Gorges Dam, and belongs to subtropical zone continental monsoon climate, which summer longer than winter and abundant in natural resources. XiangXi watershed exist a series of ecological environment problems like soil and water erosion, flood disaster or environmental degradation in the process of economic development, it's necessary to carry out relevant relevant regulation measures. The location of XiangXi watershed is shown in Fig. 1.

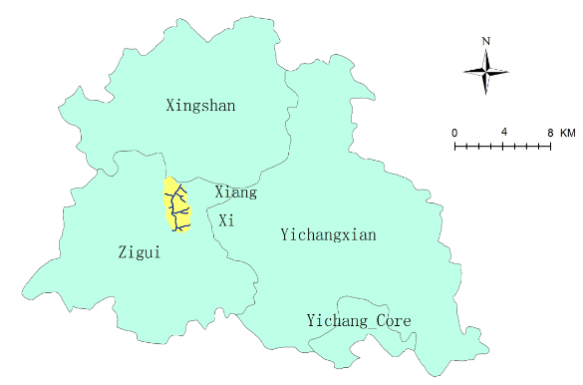

Fig. 1. Geographic location of study region.

\section{B. Technical Roadmap}

The datasource including multi-temporal remote sensing images of GF1. Soil and water erosion factors such as vegetation coverage, land-use type, human-caused erosion. Topographic slope factor like 1:50 000 DEM provided by Geospatial Data Cloud Website [5].

The technical roadmap can be described as follows. Firstly, conducting spatial overlay analysis based on Arcgis to generate water and soil erosion intensity map of different temporal towards vegetation coverage, land-use type and slop data. Then calculating the erosion area by statistical function. Finally, constructing change transfer matrix to analyze the dynamic changes of various erosion area. The overall technical route is shown in Fig. 2.

\section{EROSION FACTOR EXTRACTION}

\section{A. Land-Use Information Extraction}


Classifying the land-use patters into 12 first-class and 57 second-class by adopting standard specifications of $\mathrm{GB} / \mathrm{T}$
21010-2007, SL592-2012 et al. Classification standard was shown in Table I.

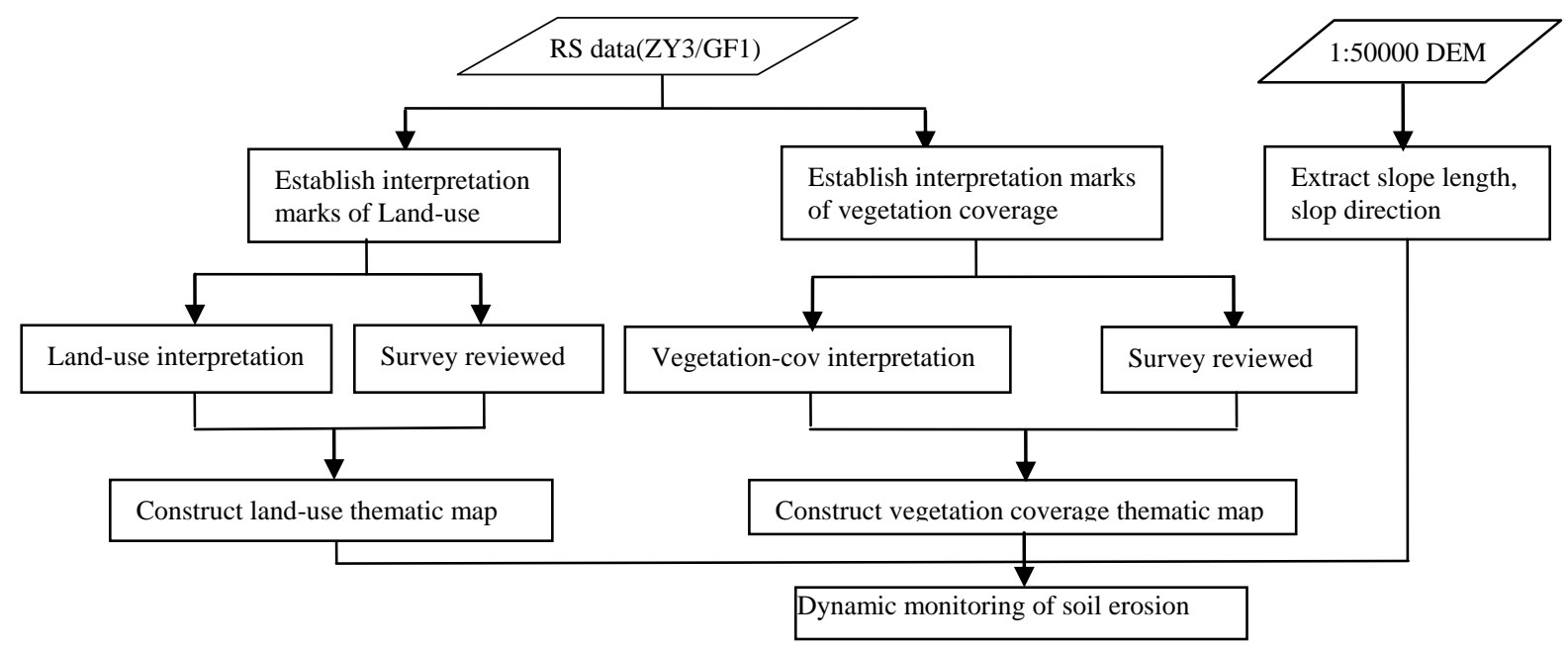

Fig. 2. Framework of Soil erosion dynamic monitoring.

TABLE I: CLASSIFICATION STANDARD OF LAND-USE

\begin{tabular}{llll}
\hline \hline First-class & Second-class & BGF-code & Temp-code \\
\hline \multirow{4}{*}{ Farmland } & Paddyland & 11 & 11 \\
& & 16 & 160 \\
Gardenland & Dryland & 17 & 17 \\
Forestland & Orchard or tea & 23 & $211 \sim 235$ \\
Grassland & Forest & 30 & $31 \sim 35$ \\
& Grass & 40 & $41 \sim 45$ \\
Commercial- land & Shrub & 90 & $91 \sim 95$ \\
Transportation & Settlement & 52 & 52 \\
Waters & Industrialland & 53 & 531,532 \\
Other land & Railway/road & 60 & $61 \sim 66$ \\
\hline \hline
\end{tabular}

The land-use types extraction results of 2016 to 2017 were shown in Fig. 3.

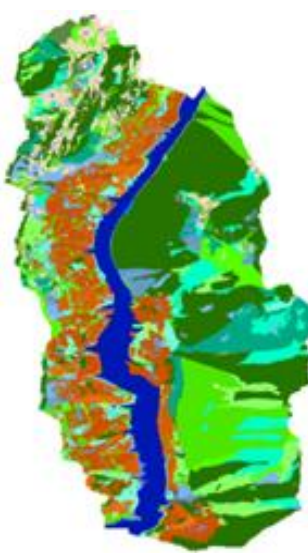

(a) 2016

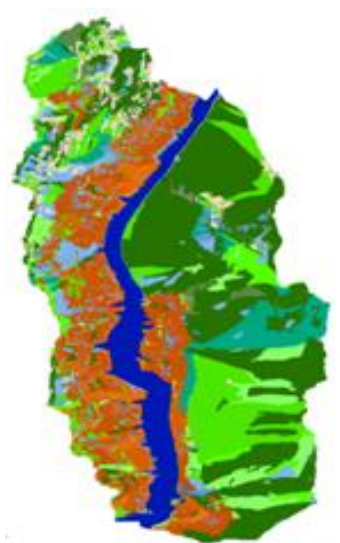

(b) 2017
Land-use type

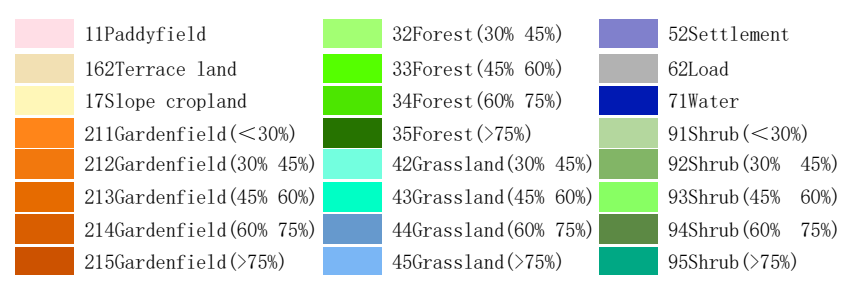

Fig. 3. Extraction results of Land-use type in 2016 and 2017.

The change results were shown in Table II. Statistical results shown that the land-use pattern was slightly structural adjustment from 2016 to 2017, the revegetated grassland was biggest decreasing magnitudes, which hold the line with the increasing magnitudes of forestland and gardenland. It reflected the tendency of reclamation and afforestation. Industrial and traffic land increased slightly, mainly derived from farmland conversion, while two periods of river and bareland kept flat, it was also consistent with the local water conservation measures and field reconnaissance.

\begin{tabular}{|c|c|c|c|c|}
\hline $\begin{array}{l}\text { Land } \\
\text { use }\end{array}$ & $\begin{array}{l}\text { BGF } \\
\text { code }\end{array}$ & $\begin{array}{l}2016 \\
\text { Area }\end{array}$ & $\begin{array}{l}2017 \\
\text { Area }\end{array}$ & $\begin{array}{c}\text { Change } \\
\text { Percentage }\end{array}$ \\
\hline Dryland & 16 & 4.04 & 3.07 & $-0.98 \%$ \\
\hline Slopeland & 17 & 0.30 & 0.19 & $-0.11 \%$ \\
\hline Garden & 23 & 16.91 & 21.21 & $4.31 \%$ \\
\hline Forest & 30 & 41.97 & 44.89 & $2.92 \%$ \\
\hline Grass & 40 & 14.13 & 6.39 & $-7.74 \%$ \\
\hline Shrub & 90 & 11.50 & 12.48 & $0.98 \%$ \\
\hline Settlement & 52 & 1.11 & 1.28 & $0.17 \%$ \\
\hline Indusland & 53 & 0.19 & 0.22 & $0.03 \%$ \\
\hline Road & 60 & 0.80 & 1.13 & $0.33 \%$ \\
\hline River & 70 & 8.94 & 8.95 & $0.01 \%$ \\
\hline Bareland & 80 & 0.05 & 0.12 & $0.07 \%$ \\
\hline
\end{tabular}

\section{B. Vegetation Coverage Information Extraction}

Vegetation coverage is the main indicator to affect soil erosion [6]. Adopting interactive visual interpretation based on standard of SL 592-2012 [7] to extract vegetation coverage information, and to calculate variation of vegetation cover by using Arcgis. The extraction results of 2016 to 2017 were shown in Fig. 4.

TABLE III: RESUlTS OF VEGETATION COVERAGE IN STUDY REGION

\begin{tabular}{lcccc}
\hline \hline \multirow{2}{*}{$\begin{array}{l}\text { vegetation } \\
\text { coverage }\end{array}$} & 2016 & 2017 & \multicolumn{2}{c}{ Changes } \\
\cline { 5 - 5 } & Area & Area & Variation & Percentage \\
\hline High-cov & 35.75 & 42.24 & +6.49 & $+9.60 \%$ \\
Moderate-High & 13.37 & 15.54 & +2.17 & $+3.21 \%$ \\
Moderate-cov & 13.04 & 8.23 & -4.80 & $-7.11 \%$ \\
Low-Moderate & 5.28 & 1.50 & -3.79 & $-5.60 \%$ \\
$\quad$ Low-cov & 0.16 & 0.09 & -0.07 & $-0.10 \%$ \\
\hline \hline
\end{tabular}

The vegetation coverage results of 2016 and 2017 were shown in Table III. Result shown that in 2017, High coverage 
increased $6.49 \mathrm{~km}^{2}$ accounted for 9.6\%, while Moderate-High coverage increased $2.17 \mathrm{~km}^{2}$ accounted for $3.21 \%$ compared with 2016 , which were mainly transformed from Moderate coverage and Low-Moderate coverage. It reflected the tendency of better ecologica environment.

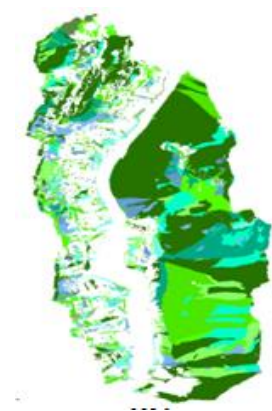

(a) 2016

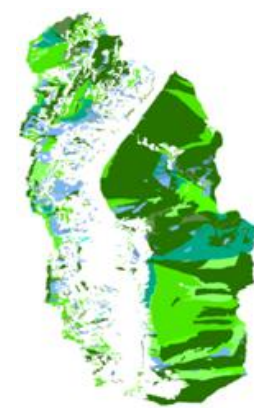

(b) 2017
Vegetation coverage

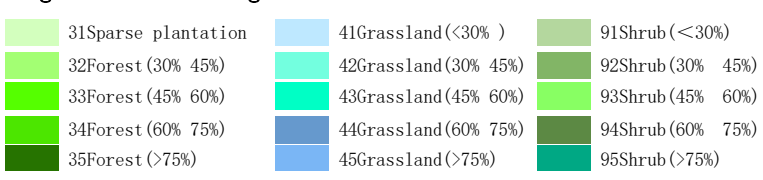

Fig. 4. Vegetation coverage results in 2016 and 2017.

\section{Slope Information Extraction}

Terrain is the basic natural geographical factor and can effect human production, which is mainly including slope length, slope shape and slope direction. In general, the more complex the terrain, the worse the water loss [8]. Slop is closely related to soil erosion, which is not only the main factor to affect soil erosion, but also the key determinant of slope surface erosion. The conventional method including percentage and degree method. The slope formula based on small watershed was shown as below.

$$
S=\left\{\begin{array}{lc}
10.8 \sin \theta+0.03 & \theta<0.5^{\circ} \\
16.8 \sin \theta-0.5 & 0.5^{\circ} \leq \theta<10^{\circ} \\
21.9 \sin \theta-0.03 & \theta \geq 10^{\circ}
\end{array}\right.
$$

Slop was divided into 6 level,including $\left(0^{\circ} 5^{\circ}\right],\left(5^{\circ} 8^{\circ}\right),\left(8^{\circ}\right.$ $\left.15^{\circ}\right],\left(15^{\circ} 25^{\circ}\right],\left(25^{\circ} 35^{\circ}\right],>35^{\circ}$ according to the Technical Specification of Soil and Water Conservation. The slope classification was shown in Table IV.

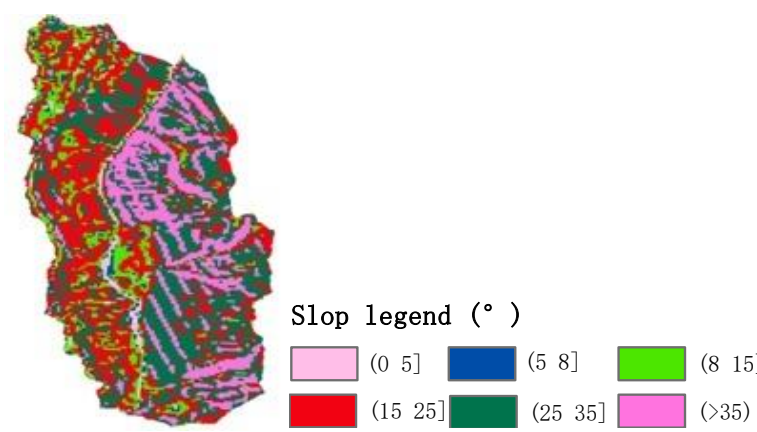

Fig. 5. Slop distribution results.

The paper generated slope map by using 1:50 000 DEM, then resampling to normalize scale. The result was shown in Fig. 5.

Statistics results of different slope was shown in Table V. The terrain were flat relatively, of which mainly belong to alpine foothills. Flat slope $\left(0^{\circ} 5^{\circ}\right.$ ) account for $2.10 \%$, Gentle slope $\left(5^{\circ} 8^{\circ}\right.$ ] account for $2.34 \%$, Continental slope $\left(8^{\circ} 15^{\circ}\right]$ account for $11.65 \%$, Abrupt slope $\left(15^{\circ} 25^{\circ}\right.$ ] account for $31.95 \%$, Steep slope $\left(25^{\circ} 35^{\circ}\right.$ ] account for $34.03 \%$, Slippery slope $\left(>35^{\circ}\right)$ account for $17.93 \%$.

\begin{tabular}{lcccccc}
\multicolumn{7}{c}{ TABLE IV: ClASSIFICATION TABLE OF SLOPE } \\
\hline \hline $\begin{array}{c}\text { Flat } \\
\text { slope }\end{array}$ & $\begin{array}{c}\text { Gentle } \\
\text { slope }\end{array}$ & $\begin{array}{c}\text { Continental } \\
\text { slope }\end{array}$ & $\begin{array}{c}\text { Abrupt } \\
\text { slope }\end{array}$ & $\begin{array}{c}\text { Steep } \\
\text { slope }\end{array}$ & $\begin{array}{c}\text { Slippery } \\
\text { Slope }\end{array}$ \\
\hline $\begin{array}{l}\text { gradient } \\
\left({ }^{\circ}\right)\end{array}$ & $\left(\begin{array}{lllll}0 & 5\end{array}\right]$ & $\left(\begin{array}{llll}5 & 8\end{array}\right]$ & $\left(\begin{array}{lll}8 & 15\end{array}\right]$ & $\begin{array}{l}(15 \\
25\end{array}$ & $\begin{array}{c}25 \\
35\end{array}$ & $>35$ \\
\hline \hline
\end{tabular}

TABLE V: STATISTICAL RESULTS OF GRADIENT

\begin{tabular}{ccccccc}
\hline \hline Gradient $\left(^{\circ}\right)$ & $(05]$ & $(58]$ & $(815]$ & $(1525]$ & $(2535]$ & $(>35)$ \\
\hline Area $/ \mathrm{km}^{2}$ & 2.05 & 2.29 & 11.41 & 31.29 & 33.33 & 17.56 \\
Percentage (\%) & 2.10 & 2.34 & 11.65 & 31.95 & 34.03 & 17.93 \\
\hline \hline
\end{tabular}

\section{ANALYSIS OF SOIL EROSION}

\section{A. Soil Erosion Intensity and Spatial Distribution}

The distribution of soil erosion intensity were divided into 6 categories, including Micro-degree, Light-degree,Mediumdegree, Dought-degree, Extrem-degree, Vigorous-degree according to the Classification criteria of Soil Erosion (SL190-2007) [9] and basic research of Zhao Shanlun et al [10], Zhang Yubin et al [11]. The distribution were shown in Table VI and Table VII.

TABLE VI: SOIL EROSION CLASSIFICATION STANDARD

\begin{tabular}{|c|c|c|c|c|c|c|}
\hline \multirow[b]{2}{*}{ Forest coverage } & \multicolumn{6}{|c|}{ Soil erosion degree of Different Gradient } \\
\hline & $\left(0^{\circ} 5^{\circ}\right]$ & $\begin{array}{l}\left(5^{\circ}\right. \\
\left.8^{\circ}\right]\end{array}$ & $\begin{array}{c}\left(8^{\circ}\right. \\
\left.15^{\circ}\right]\end{array}$ & $\begin{array}{l}\left(15^{\circ}\right. \\
\left.25^{\circ}\right]\end{array}$ & $\begin{array}{l}\left(25^{\circ}\right. \\
\left.35^{\circ}\right]\end{array}$ & $>35^{\circ}$ \\
\hline$>75(\%)$ & Micro & Micro & Micro & Micro & Micro & Micro \\
\hline $60-75(\%)$ & Micro & Slight & Slight & Slight & Medium & Medium \\
\hline $45-60(\%)$ & Micro & Slight & Slight & Medium & Medium & Dought \\
\hline $30-45(\%)$ & Micro & Slight & Medium & Medium & Dought & Extrem \\
\hline$<30(\%)$ & Micro & Medium & Medium & Dought & Extrem & Vigorous \\
\hline cropland & Micro & Slight & Medium & Dought & Extrem & Vigorous \\
\hline
\end{tabular}

Overlaying the land-use, vegetation coverage and slop map to extract soil erosion intensity of XiangXi watershed during 2016 to 2017, the extraction results were shown in Fig. 6. Statistical results shown that the soil and water erosion was given priority to Micro-degree, Slight-degree, Medium-degree, of which Micro-degree occupied largest area, Slight-degree mainly distributed in the central depression area, Medium-degree mainly distributed in south-central. While Dought, Extrem and Vigorous-degree occupied less area, which mainly distributed in the steep mountains, the bareland. 
TABLE VII: OTHER TYPES OF SOIL EROSION CLASSIFICATION STANDARD

\begin{tabular}{|c|c|c|c|c|c|c|}
\hline \multirow{2}{*}{ Land-use type } & \multicolumn{6}{|c|}{ Soil erosion degree of Different Gradient } \\
\hline & $\left(0^{\circ} 5^{\circ}\right]$ & $\left(5^{\circ} 8^{\circ}\right]$ & $\left(\begin{array}{ll}8^{\circ} & 15^{\circ}\end{array}\right]$ & $\left(15^{\circ} 25^{\circ}\right]$ & $\left(25^{\circ} 35^{\circ}\right]$ & $>35^{\circ}$ \\
\hline $\begin{array}{c}\text { Water/ } \\
\text { Facilities }\end{array}$ & Micro & Slight & Slight & Slight & Medium & Medium \\
\hline Terracing/Paddyfield & Micro & Slight & Slight & Medium & Medium & Dought \\
\hline Settlement/ Transport & Micro & Slight & Medium & Medium & Dought & Dought \\
\hline Construction/ Shoals & Micro & Slight & Medium & Dought & Dought & Extrem \\
\hline Bare soil/ Bare rock & Slight & Slight & Medium & Dought & Extrem & Vigorous \\
\hline
\end{tabular}

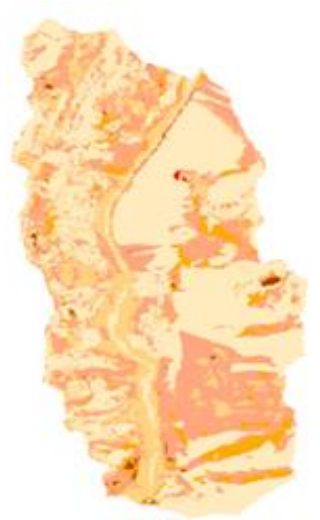

(a) 2016

Erosion Intensity

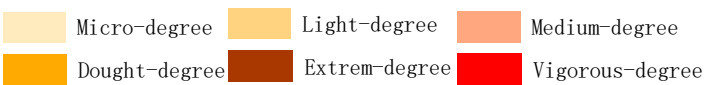

Fig. 6. Soil erosion scale of study region in 2016 and 2017.

\section{B. Change Detection Analysis of Soil Erosion}

Calculating soil erosion intensity and constructing the change transfer matrix which were shown in TABLE VIII. Statistical results shown that the tendency of soil and water erosion distribution was getting better from 2016 to 2017. Micro-degree area increased, mainly transfering from Slight-degree $\left(2.07 \mathrm{~km}^{2}\right)$, Medium-degree $\left(7.01 \mathrm{~km}^{2}\right)$ and Dought-degree $\left(1.41 \mathrm{~km}^{2}\right)$. Slight-degree erosion area kept flat. Medium-degree was slightly declined, transferred partially to Micro-degree and Slight-degree. Dought-degree was transferred partially to Micro-degree. Extrem-degree and Vigorous-degree were also partially declined.

TABLE VIII: TRANSFER MATRIX OF SOIL EROSION

\begin{tabular}{cccccccc}
\hline 2017 & $\begin{array}{c}\text { Micr } \\
\mathrm{o}\end{array}$ & $\begin{array}{c}\text { Sligh } \\
\mathrm{t}\end{array}$ & $\begin{array}{c}\text { Mediu } \\
\mathrm{m}\end{array}$ & $\begin{array}{c}\text { Doug } \\
\mathrm{ht}\end{array}$ & $\begin{array}{c}\text { Extre } \\
\mathrm{m}\end{array}$ & $\begin{array}{c}\text { Vigo } \\
\text { rous }\end{array}$ & Total \\
\hline Micro & 44.8 & 2.0 & 1.2 & 0.2 & 0.0 & 0.1 & 48.3 \\
Slight & 2.1 & 13.4 & 0.3 & 0.0 & 0.0 & 0.0 & 15.8 \\
Medium & 7.0 & 1.2 & 19.7 & 0.1 & 0.0 & 0.0 & 28.0 \\
Dought & 1.4 & 0.0 & 0.7 & 3.2 & 0.0 & 0.0 & 5.4 \\
Extrem & 0.3 & 0.0 & 0.0 & 0.0 & 0.2 & 0.0 & 0.5 \\
Vigorous & 0.0 & 0.0 & 0.0 & 0.0 & 0.0 & 0.1 & 0.1 \\
Total & 55.5 & 16.6 & 21.9 & 3.5 & 0.2 & 0.2 & 98.0 \\
\hline \hline
\end{tabular}

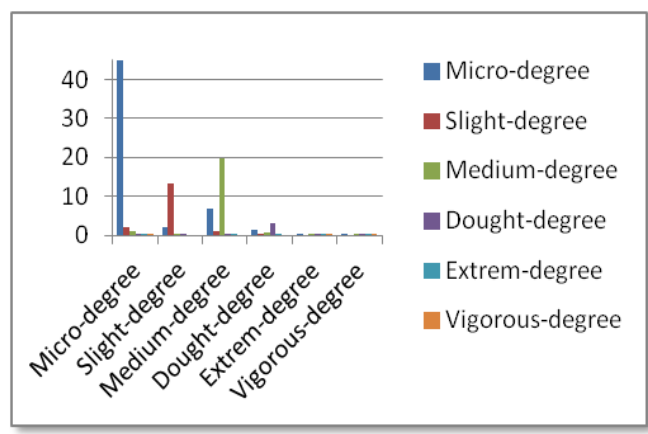

Fig. 7. Graph of soil erosion scale of study region.
Results suggested that soil and water erosion of XiangXi watershed was getting better from 2016 to 2017, the land-use pattern of study region had experienced structural adjustment, mainly reflected in that slope gravity erosion got improvement and vegetation measures such as Returning Farmland to Forest got efficiency. The erosion disturbance caused by engineering excavation was relatively small compared to the local water conservation engineering measures. Combining the water protection measures provided by local experts with the actual field investigation, XiangXi watershed adopted comprehensive management of Interception Irrigation and complementary scientific prevention mode of Horizontal Terraces-Economic Forest during 2016 to 2017, it had governed slope cropland 2.03 $\mathrm{km}^{2}$, including stone terracing of sloping land $0.41 \mathrm{~km}^{2}$, ridge terracing of sloping land $0.12 \mathrm{~km}^{2}$, repaired cross wall terraces $1.5 \mathrm{~km}^{2}$. In the meanwhile, supported the slope drainage engineering including the drain $3720 \mathrm{~m}$, the sand basin $31 \mathrm{th}$, the field road $20.1 \mathrm{~km}$. Several typical water conservation projects were shown in Fig. 7, which verified the reliability of results proposed in the paper.

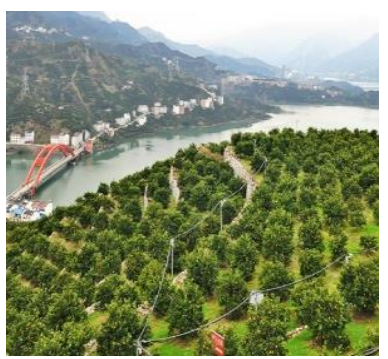

(a) Navel orange gardens

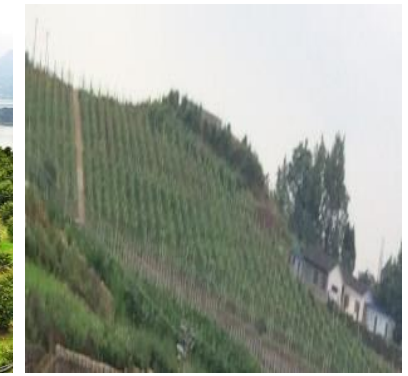

(b) Terracing economic forest
Fig. 7. Soil and water conservation project.

\section{CONCLUSION}

The paper combined remote sensing monitoring with GPS investigation based on GF1 images of multiple time-phase, and extracted the major factors affecting soil erosion like vegetation coverage, land-use type and slop data to overlap analyze soil erosion intensity and constructed change matrix to analyze dynamic changes. Results showed that the land-use patterns of XiangXi watershed from 2016 to 2017 had experienced structural adjustment ,the distribution of soil erosion were getting better, of which mainly reflected in comprehensive improvement of slope gravity erosion and efficiency of vegetation measures. It has positive connection with the local slope control engineering such as Terracing of Sloping land and Slope drainage, and also plant measures such as Returning Farmland to Forest and Planting Navel orange gardens. 


\section{REFERENCES}

[1] Z.-Y. Shao, "Study on the Soil erosion monitoring based on high resolution remote sensing image [J]," Soil and Water Conservation, 2010, vol. 2, pp. 11-12.

[2] D. Haboudane, F. Bonn, A. Royer et al., "Land degradation and erosion risk mapping by fusion of spectrally-based information and digital geomorphometric attributes [J]," International Journal of remote sensing, 2002, vol. 23, no. 18, pp. 3795-3820.

[3] P.-X. Zhao et al., "Methods on application of "3S" technology in returning farmlands to forests in the small drainage areas of the loess plateau," Journal of Northwest Forestry University, 2003, mo. 1, pp. 96-98.

[4] F. Xu, "Application of remote sensing technology in the soil and water conservation monitoring for construction projects-taking HongJiaDu hydropower station as an example," Soil and Water Conservation, 2008, no. 312, pp. 42-44+64.

[5] Geographic Space date cloud. [Online]. Available: http://www.gscloud.cn/sources/Cdataid=302 \&pdataid $=10$

[6] Y.-M. Zhou, "Study on methods for water conservation monitoring small watershed-oriented," Institute of Remote Sensing Information Applications Chinese Academy of Sciences, Beijing, 2005.

[7] Water resources ministry of rural water conservancy department of soil and water conservation, "Soil and water conservation technical specification," Beijing: Water Conservancy and Electric Power Press, 1988, pp. 89-90.

[8] J. R. Ni et al., "Characteristics analysis of the loess slope surface rill development based on the self-organization theory [J]," Journal of Hydraulic Engineering, 2002, vol. 1, pp. 6-9.

[9] Ministry of Water Resources, "Soil erosion classification standard," Beijing: China Water\& Power Press, 2008.

[10] S.-L. Zhao et al., "An analysis on the spatial features of soil erosion in Shandong Province based on GIS[J]," Scientia Geographica Sinica, 2002, vol. 22, no. 6, pp. 694-699.

[11] Y. B. Zhang, "The suppervising information system of county scope for water and soil losses-using the data of Nanzhang county as the sample [D]," Beijing: Graduate School of Chinese Academy of Sciences, 2002.

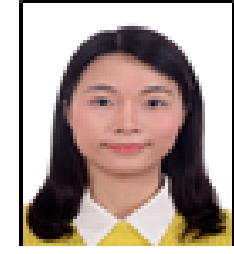

Ying Jiang was born in 1990 in Hunan province of China. She had the master degree of photogrammetry and remote sensing at the Wuhan University in 2016. She is an engineer in Changjiang River Scientific Research Institute, Wuhan, China, and mainly engaged in application of water conservancy informatization, especially in the soil erosion and ecological environment dynamic monitorring.

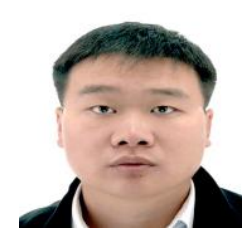

Daxiang Xiang was born in 1984 in Hubei province of China. He had the PhD degree of photogrammetry and remote sensing at the Wuhan University in 2011 He is a senior engineer in Changjiang River Scientific Research Institute, Wuhan, China, and mainly engaged in remote sensing analysis of meteorological drought.

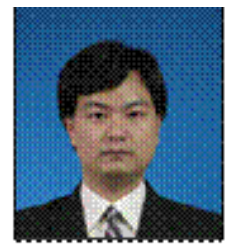

Zhe Li was born in 1980 in Hubei province of China. He had the $\mathrm{PhD}$ degree of earth and Space sciences at the Peking University in 2009. He is a senior engineer and chief officer in Changjiang River Scientific Research Institute, Wuhan, China, and mainly engaged in digital watershed space-time information organization and transmission system research.

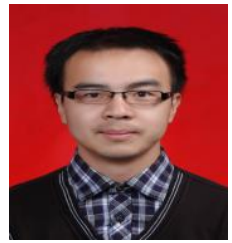

Xiong Fei Wen was born in 1984 in Hubei province of China. He had the PhD degree of photogrammetry and remote sensing at the Wuhan University in 2011. $\mathrm{He}$ is a Senior engineer in Changjiang River Scientific Research Institute, Wuhan, China, and mainly engaged in application of Water conservancy informatization.

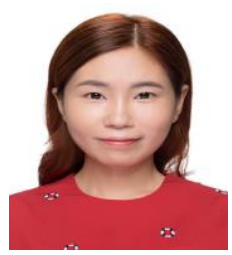

Xichi Chen was born in 1990 in Hubei province of China. She had the master degree of Marine engineering at the Wuhan Technology University in 2015. She is an engineer in Changjiang River Scientific Research Institute, Wuhan, China, and mainly engaged in application of Water conservancy informatization. 